\title{
The Threshold Effect of Inflation on Capital Market Performance: A Case of Ghana Stock Exchange
}

\author{
David Mensah Awadzie \\ AIT Business School, Accra Institute of Technology, Accra, Ghana
}

Email address:

davidawadzie@gmail.com

\section{To cite this article:}

David Mensah Awadzie. The Threshold Effect of Inflation on Capital Market Performance: A Case of Ghana Stock Exchange. Journal of Business and Economic Development. Vol. 5, No. 4, 2020, pp. 199-207. doi: 10.11648/j.jbed.20200504.11

Received: September 26, 2020; Accepted: October 15, 2020; Published: October 30, 2020

\begin{abstract}
The purpose of this study is to investigate the threshold effect of inflation on capital market performance. The study employed a Threshold Autoregressive model introduced by Tong (1978) and Hansen (1996). The study used secondary quarter-time series data for thirty-years from 1990 to 2019. The capital market performance was measured by the value of shares traded; market turnover; market capitalization and all-shares index. However, the results revealed the following estimated threshold level of inflation for each performance indicator: $3.77 \% ; 4.12 \% ; 4.15 \%$, and $4.22 \%$ respectively. In all, the threshold level of inflation estimated was between 3 to $4 \%$. The findings suggest that low inflation is performance-enhancing. Besides, inflation above the threshold level is detrimental to the capital market performance. The study further concluded that the exchange rate equally affects the performance of the capital market. The findings of this investigation might be helpful to the government of Ghana and policymakers as they settle on an inflation target to adopt to avoid the detrimental effects of high inflation while obtaining the growth benefits of low inflation.
\end{abstract}

Keywords: Capital Market Performance, Inflation, Threshold Autoregressive, Market Capitalization All-Shares Index, Turnover Ratio

\section{Introduction}

\subsection{Background of the Study}

Economic growth is a concern to every nation and one of the key institutions that contribute to economic growth is the capital market. This is because it plays a very important role in mobilizing long-term capital for developmental projects. [7], indicated that the capital market is an institution that contributes to the socio-economic growth and development of emerging and developed economies. This is possible because of the intermediary role played by the capital market in mobilizing funds from surplus units to deficits units to be invested in projects with positive net present value (NPV) which may enhance the economic growth of the nation. [25] also revealed that the capital market is a vehicle of any economy to growth and development because it is vital for long-term growth capital formation. It is crucial in the mobilization of savings and channeling of such funds, i.e. savings to profitable self-liquidating investment. The capital market offers access to a variety of financial instruments that enable economic agents to pool, price, and exchange risk. Through assets with attractive yields, liquidity, and risk characteristics, it encourages savings in financial form.

According to [24], the capital market is essential for the government and other institutions in need of long-term funds and suppliers of long-term funds. A unique benefit of the capital market to corporate entities is the provision of long-term, non-debt financial capital. Given its significance in quickening monetary development and advancement, the government of most countries, in general, will have a distinct fascination for the presentation of its capital market. "Investment in the capital market is long term in nature; hence any development that could affect the stability of the economy usually has a serious impact on the performance of the stock market [8]". However, [6] pointed out that the inflation rate amongst others as a factor that could influence the market performance.

Inflation is a quantitative measure of the rate at which the average price level of a basket of selected goods and services in an economy increases over some time. It is the rise in the general level of prices where a unit of currency effectively buys less than it did in prior periods. Often expressed as a 
percentage, inflation, thus indicates a decrease in the purchasing power of a nation's currency. Inflationary environments make it difficult to build up prospective savings, investment, production and consumption decisions, and an environment of increasing uncertainty prevents economic growth. Repetitive price increase erodes the purchasing power of money and other financial assets with fixed values, creating serious economic distortions and uncertainty.

With an increase in inflation, every sector of the economy is affected. Ranging from unemployment, interest rates, exchange rates, investment, and stock markets. There is an aftermath of inflation in every sector. Inflation is bound to impact all sectors, either directly or indirectly. Inflation and the stock market have a very close association. If there is inflation, stock markets are the worst affected [10]. If inflation is a major obstacle in promoting economic growth, then it readily follows that policymakers should aim at a low rate of inflation [21, 21] again mention that, if a non-linear relationship exists between inflation and growth, then it should be possible to estimate the threshold, or inflection point, at which the sign of the relationship between the two variables would switch.

\subsection{Problem Statement}

The literature is heavily weighted with studies estimating threshold of inflation on economic growth in developed and developing countries e.g. [9, 2-4, 31, 29, 18-22]. However, not many studies have been done on the subject in Sub Saharan Africa. Some recent studies on the subject in Sub-Saharan Africa are [12, 1, 23]. Again, these research works have produced mixed results and it has been revealed that no work about the subject has been carried in the area of the capital market, hence the need for this paper.

\subsection{Objectives of the Study}

The objectives of the study are as follow:

1. To investigate the extent to which inflation rate fluctuations impact on the value of shares traded.

2. To determine the effect of the inflation rate on the market turnover ratio.

3. To examine the impact of inflation rate fluctuation on the market capitalization of shares traded.

4. To investigate the extent to which inflation rate fluctuations impact on all - shares index.

5. To examined if any other macroeconomic variables can affect capital market performance apart from inflation.

\subsection{Research Questions}

This research work seeks to answer a wide range of questions and the following research questions will be considered in this work.

i. What is the effect of inflation on the value of shares traded under the different inflationary regime?

ii. Is there a statistically significant threshold level of inflation above which inflation is harmful to the turnover ratio? iii. Is there a statistically significant threshold level of inflation above which inflation is harmful to market capitalization?

iv. Is there a statistically non - linear relationship between inflation and all - shares index; in other words, is there a threshold level of inflation above which inflation affects all - shares index?

v. Are there any other macroeconomic variables that can affect capital market performance apart from inflation?

\section{Literature Review}

\subsection{Theoretical Review}

In the framework of Keynesianism, the aggregate demand (AD) and aggregate supply (AS) curves are adopted to show the relationship between output and inflation. According to Keynesian, in the short run, the AS curve is upward sloping rather than vertical. If the AS curve is vertical, changes on the demand side of the economy affect only prices. However, if it is upward sloping, changes in $\mathrm{AD}$ affect both price and output. This holds with the fact that many factors, such as expectations, prices of other factors of production, fiscal and monetary policy, drive the inflation rate, and the level of output in the short-run. When the general prices increase Producers of a certain product feel that only the prices of their products have increased while the other producers are operating at the same price level. However, in reality, overall prices have risen. Thus, the producer continues to produce more and output continues to rise. It reveals that according to Keynesian there exists a positive effect of price increases in output at least in the short-run [28].

Monetarism speaks of the followers of M. Friedman (1912-2006) who opines that "only money matters", and as such monetary policy is a more potent instrument than fiscal policy in economic stabilization. According to the monetarists, the money supply is the "dominant, though not exclusive" determinant of both the level of output and prices in the short run and of the level of prices in the long run. The long-run level of output is not influenced by the money supply. The monetarists emphasized the role of money. Milton Friedman's modern quantity theory holds that "inflation is always and everywhere a monetary phenomenon that arises from a more rapid expansion in the quantity of money than in total output. Its earliest explanation was to be found in the simple quantity theory of money.

\subsection{Empirical Review}

The studies reviewed so far have indicated that inflation is a major obstacle in promoting economic growth, therefore, it is a prerequisite of policymakers to aim at mitigating inflation to a lower rate. But the question is what should be the target level of inflation? Again, how low should inflation be in the capital market to have a positive impact on economic growth? In other words, if a non-linear relationship exists between inflation and growth, then it should be possible to estimate the threshold, or inflection point, at which the sign of the 
relationship between the two variables would switch. The study about the relationship between inflation and economic growth can be looked out in two ways, which is a linear and non-linear model.

The first few studies that investigated the possibility of non-linear relationships are $[11,26]$. In their studies, they found structural breakpoints. [11], found the existence of a positive relationship between long-run growth and inflation at a low rate of inflation, but at higher rates it becomes negative. After [11] research, other studies among others [19] found threshold inflation in a developed country is $1-2 \%$ and developing country is $11-12 \%$. [20] found $2 \%$ in industrializing countries and $17 \%$ for non-industrialized countries. [31] found $5.43 \%$ in 32 Asian countries. [3] found a $12 \%$ threshold of inflation in developing countries. Then, [2] found $13.48 \%, 14.48 \%, 15.37 \%$, and $40 \%$ for aggregate GDP, industrial, services, and agriculture sectors respectively; [23] found an inflation threshold of $6.7 \%$ for the whole sample, $9 \%$ of the sub-sample of low-income countries and $6.5 \%$ for middle-income countries.

Furthermore, few studies have examined the threshold level and the relationship between inflation and economic growth in Ghana. These are [10] using threshold regression models designed to estimate the inflation thresholds instead of imposing them, have obtained $10 \%$ for Ghana whereas, [1] using the conditional least squares technique found $11 \%$ for Ghana. Again, different threshold or mixed results in inflation level may have been caused by using data from the different economic jurisdictions of varying economic trends and conditions. [27, 20] mention that the study of inflation and economic growth should be the focus in the country because of the economic structure of each country is different.

Besides, some studies have examined the same country but have obtained different results for a different time period that may likely due to the economic structure of the country over time. It has also been noted that there is no specific study has yet been undertaken on the threshold effect of inflation on capital market performance. Although, the capital market has been one of the sectors that form an integral part of economic growth. However. the focus of data for this study is on Ghana.

\section{Research Methodology}

The methodology used in this study is based on the threshold autoregressive (TAR) approach proposed by [30, 14]. In this model, the dependent variable is a function of its lag. In the self -exciting threshold model, the lagged dependent variable is used as the threshold variable. This model specifies that individual observations can fall into discrete classes based on the value of an observed (threshold) variable. In growth theory, the main sources of growth power lie in the accumulation of the factor of production, and the promotion of marginal productivity and total factor productivity.

The recent literature has instituted that the relationship between financial development and economic growth does not follow a single pattern. For example, $[17,13,5]$ have found that inflation affects real variables through its impact on financial market activities. To examine the effects of the interaction between inflation on capital market performance, the study employed the TAR model proposed by $[30,14]$.

In the TAR model, the classification of the variable across regimes is based on an estimate of the time series behavior that is consistent with reaching the threshold that separates the regimes. This study applies the Autoregressive model to estimate the threshold level of inflation above which inflation may affect capital market performance. The threshold level of inflation is based on the following equation:

$$
Y_{t}=\beta_{1}^{\prime} \times_{t} h(q t \geq y)+\beta_{2}^{\prime} \times_{t} h(y<q t<y)+\varepsilon_{t}
$$

Where $\gamma_{t}$ is the dependent variable, $\times_{t}$ is a $1 \mathrm{x} \mathrm{k}$ vector of covariates possibly containing lagged values of $\gamma_{t}, \beta_{1}^{\prime}$ is a $\mathrm{kx}$ 1 vector of regime-invariant parameters, $\varepsilon_{t}$ is an iid error with mean 0 and variance $\sigma^{2}, h$ is a vector of exogenous variables with regime-specific coefficient vectors $\beta_{1}^{\prime}$ and $\beta_{2}^{\prime}$, and $q_{\mathrm{t}}$ is a threshold variable that may also be one of the variables in $x_{t}$. Regime 1 is defined as the subset of observations in which the value of being $q_{\mathrm{t}}$ less than the threshold $\gamma$. Similarly, Regime 2 is defined as the subset of observations in which the value of $q_{\mathrm{t}}$ is greater than $\gamma$.

$$
\begin{gathered}
\gamma_{t}=\beta_{1}^{\prime} \times_{t} h+\varepsilon_{t} \text { if } \mathrm{q}_{\mathrm{t}} \leq \gamma \\
\gamma_{t}=\beta_{2}^{\prime} \times_{t} h+\varepsilon_{t} \text { if } \mathrm{q}_{\mathrm{t}}>\gamma
\end{gathered}
$$

Where $q_{t}$ signifies the threshold variable, dividing all the observed values into two groups or "regimes". Term $\gamma_{t}$ signifies the variable to be explained, whereas is a matrix that, denotes the explanatory variable. The error term $\varepsilon_{t}$ is white-noise iid, and $\gamma$ represents the threshold value, which is unknown, but can be estimated. The model implies that when the threshold variable is smaller than the threshold parameter, the regression Equation (2) is applicable. Let $h_{t}(\gamma)=\left\{\mathrm{q}_{\mathrm{t}} \leq \gamma\right\}$, and $\{$.$\} as an indicator function with h=1$ if $\mathrm{q}_{\mathrm{t}} \leq \gamma$ occurs, or $h=0$ otherwise. In addition, when $\times_{t}(\gamma)=\times_{t} h_{t}(\gamma)$, the equations (2) and (3) revised as follows.

$$
\gamma_{t}=\theta^{\prime} x_{t}+\rho^{\prime} x_{t}(\gamma)+e_{t}, e_{t} \sim \operatorname{iid}\left(0, \sigma_{t}^{2}\right) .
$$

Therein, $\theta=\theta_{2}, \rho=\theta_{1}-\theta_{2}, e_{t}=\left[e_{1 t} e_{2 t}\right]^{\prime} \theta, \rho$, and $\gamma$ are the parameters to be estimated. The equation (4) allows all the regression coefficients to differ between sample groups. The resulting sum of squared error as a result of estimating these parameters $\theta, \rho$, and $\gamma$ can be expressed as follows

$$
S_{1}(\gamma)=\hat{\mathrm{e}}(\gamma)^{\prime} \text { ê }(\gamma)
$$

The least-squares method for estimating $\gamma$ was introduced by Hansen in (1996). This can be achieved by minimizing the sum of squared errors in (5). The estimated threshold value is given as:

$$
\hat{\gamma}=\operatorname{argmin} S_{1}(\gamma)
$$

And the variance of the residual is expressed as:

$$
\hat{\sigma}^{2}=\frac{1}{n} \hat{\mathrm{e}}_{t}(\gamma)^{\prime} \hat{\mathrm{e}}_{t}(\gamma)=\frac{1}{n} s_{1}(\hat{\gamma})
$$


Once $\hat{\gamma}$ is obtained, the vector of parameter estimates is $\hat{\theta}=\hat{\theta}(\hat{\gamma})$ and $\hat{\rho}=\hat{\rho}(\hat{\gamma})$. The regression equation for a two-regime TAR model can be expressed as:

Total Value of Shares Traded

$$
\begin{aligned}
& \text { MTVS }_{t}=\beta_{10} \text { infl }+\beta_{11} \text { intr. }+\beta_{12} \text { exchr. }+\varepsilon_{t} \text { if } \leq \gamma \\
& \text { MTVS }_{t}=\beta_{20} \text { infl }+\beta_{21} \text { intr. }+\beta_{24} \text { exchr. }+\varepsilon_{t} \text { if }>\gamma
\end{aligned}
$$

Market Turnover Ratio

$$
\begin{gathered}
\operatorname{MTOR}_{t}=\beta_{10} \text { infl }+\beta_{11} \text { intr. }+\beta_{12} \text { exchr. }+\varepsilon_{t} \text { if } \leq \gamma \\
\operatorname{MTOR}_{t}=\beta_{20} \text { infl }+\beta_{21} \text { intr. }+\beta_{24} \text { exchr. }+\varepsilon_{t} \text { if }>\gamma
\end{gathered}
$$

\section{Market Capitalization}

$$
\begin{gathered}
\mathrm{MCA}_{t}=\beta_{10} \text { infl }+\beta_{11} \text { intr. }+\beta_{12} \text { exchr. }+\varepsilon_{t} \text { if } \leq \gamma \\
\text { MCA }_{t}=\beta_{20} \text { infl }+\beta_{21} \text { intr. }+\beta_{24} \text { exchr. }+\varepsilon_{t} \text { if }>\gamma
\end{gathered}
$$

\section{Market Turnover Ratio}

$$
\begin{aligned}
& \text { ASI }_{t}=\beta_{10} \text { infl }+\beta_{11} \text { intr. }+\beta_{12} \text { exchr. }+\varepsilon_{t} \text { if } \leq \gamma \\
& \text { ASI }_{t}=\beta_{20} \text { infl }+\beta_{21} \text { intr. }+\beta_{24} \text { exchr. }+\varepsilon_{t} \text { if }>\gamma
\end{aligned}
$$

In the assessment of the model above, the threshold value is determined by obtaining the threshold value that limits the entirety of the squared error given by Equation (5). Since the reason for this paper is to examine the inflationary threshold impacts in the connection between valuation and capital market performance, the quarterly growth rate of inflation is utilized as the core threshold variable in the examination. Before we apply the two-regime Threshold Autoregression (TAR) model, we have to test for the threshold impacts. In this situation, it is undifferentiated from testing the null hypothesis of the linear model against the alternative hypothesis of the two-regime model, for the equation.

Ordinary techniques for theory testing can't be applied, in light of the trouble with the threshold boundary $\gamma$ being unidentified under the null hypothesis. For this situation, the basic appropriation of a huge example isn't dispersed by Chi-square dissemination. [15] proposed an answer to this specific issue and recommended that important tests be led using a Lagrange Multiplier $(L M)$ bootstrap technique. For $\gamma$ isn't distinguished under the invalid speculation of the no-threshold impact, the p-values are registered by a fixed bootstrap technique. To analyze by testing whether the coefficients in the two regimes are the equivalent or not, the null hypothesis of no threshold impact to Equation is.

$$
H_{0}=\beta_{1 i}=\beta_{2 i} i=0 \ldots \ldots 5
$$

Let $S_{0}$ and $S_{1}$ be the residual sum of squares under the null hypothesis and alternative of (16). As such, the $F$-test is based on:

$$
F_{1}=\frac{S_{0}-S_{1}(\gamma)}{\hat{\sigma}^{2}}
$$

Once the threshold effect exists, the next question is whether or not the threshold value can be known. The null hypothesis of the threshold value is $H_{0}: \gamma=\gamma_{0}$, and the likelihood ratio statistics is:

$$
L R_{1}(\gamma)=\frac{s_{1}(\gamma)-s_{1}(\gamma)}{\hat{\sigma}^{2}}
$$

Where $S_{1}(\gamma)$ and $S_{1}(\gamma)$ are the residual sum of squares from Equation (7) given the true and estimated value, respectively. The asymptotic distribution of $L R_{1}\left(\gamma_{0}\right)$ can be used to form a valid asymptotic confidence interval about the estimated threshold values. The statistics of $L R_{1}\left(\gamma_{0}\right)$ are not normally distributed and Hansen (2000) computed their no-rejection region, $c(\alpha), \alpha$ is a given asymptotic level. That is, if $L R_{1}\left(\gamma_{0}\right) \leq c(\alpha)$, where $c(\alpha)=-2 \operatorname{In}(1-\sqrt{1-a})$, the null hypothesis of $H_{0}: \gamma=\gamma_{0}$ cannot be rejected.

Aside from testing the existence of one threshold value, to further investigate whether there are two or more threshold values that exist, we first employ the $F_{1}$ test to assess the null hypothesis of no threshold. If this null hypothesis is rejected, then at least one threshold value is ensured. We next proceed to test the null of one threshold against the two thresholds. We assume a known estimated $\hat{\gamma_{1}}$ and proceed to search the second threshold, $\gamma_{2}$. In this case, we obtain the following:

$$
\begin{gathered}
S_{2}^{r}\left(\gamma_{2}\right)=S\left(\hat{\gamma}_{1}, \gamma_{2}\right) \text { if } \hat{\gamma}_{1}<\gamma_{2} \\
S\left(\gamma_{2}, \hat{\gamma}_{1}\right) \text { if } \gamma_{2}<\hat{\gamma}_{1}
\end{gathered}
$$

The threshold value, the null hypothesis, and the $F$-test are respectively stated as follows:

$$
\begin{gathered}
\hat{\gamma}_{2}^{r}=\arg \min S_{2}^{r}\left(\gamma_{2}\right), \\
H_{0}=\text { only one threshold } \\
F_{2}=\frac{S_{1}\left(\hat{\gamma}_{1}\right)-S_{2}^{r}\left(\hat{\gamma}_{2}^{r}\right)}{\hat{\sigma}_{2}^{2}}
\end{gathered}
$$

Where $S_{1}\left(\hat{\gamma}_{1}\right)$ is referred to as the sum of squared errors acquired from the previous threshold estimation. The residual variance is given as follows:

$$
\hat{\sigma}_{2}^{2}=\frac{1}{T} S_{2}^{r}\left(\hat{\gamma}_{2}^{r}\right)
$$

The significance $F_{2}$ implies the rejection of the null of one threshold and two thresholds is expected. If the two thresholds cannot be rejected, then the confidence interval for two thresholds $\left(\gamma_{1}, \gamma_{2}\right)$ can be constructed in the same way. The procedures are carried out until the null in (16) can no longer be rejected.

\section{Presentation and Analysis of Results}

\subsection{Introduction}

This section focuses on the empirical estimation, presentation and economic interpretation of the regression results carried out using the methodology highlighted in the previous section.

Table 1. below, shows some descriptive statistics of the 
dependent and explanatory variables that were used in the study for the period 1990 to 2019 . The inflation rate is at $5.34 \%$ as compared with other explanatory variables such as exchange rate and interest rate whose rate is at $1.69 \%$ and $3.81 \%$ respectively. The average inflation rate shows in table 1 below is $3.92 \%$.

Table 1. Descriptive Statistics.

\begin{tabular}{|c|c|c|c|c|c|c|c|}
\hline & NTVS & NMTOT & NMCA & NSAI & NINF & NEXCH & NINT \\
\hline Mean & 1.737178 & -4.680262 & 6.417439 & 8.089632 & 3.925201 & -0.340263 & 3.128361 \\
\hline Median & 2576422 & -4.730551 & 7.878682 & 8.286252 & 3.892840 & -0.099084 & 3.135494 \\
\hline Maximum & 6.130813 & -2.409566 & 9.730751 & 10.38559 & 5.348060 & 1.698443 & 3.806663 \\
\hline Minimum & -6.151633 & -6.924473 & -0.460449 & 4.850936 & 3.167161 & -3.370668 & 2.564949 \\
\hline Std. Dev. & 2.885501 & 0.969509 & 3.071229 & 1.394657 & 0.509607 & 1.395214 & 0.380704 \\
\hline Skewness & -1.110708 & 0.119739 & -0.642786 & -0.599826 & 0.743054 & -0.558599 & 0.300924 \\
\hline Jarque-Bera & 27.74165 & 1.226622 & 10.05004 & 07.493338 & 10.83282 & 7.622932 & 6.797558 \\
\hline Probability & 0.000001 & 0.541555 & 0.006571 & 0.023596 & 0.004443 & 0.022116 & 0.033414 \\
\hline Observations & 117 & 117 & 117 & 117 & 117 & 117 & 117 \\
\hline
\end{tabular}

\subsection{Correlation Matrix}

The correlation analysis was performed to measure the strength and direction of the linear relationship between the two variables.

In the results, the correlation between inflation and the total value of shares, market turnover ratio, market capitalization, and all-shares index are $-0.370,0.352,-0.459$, and -0.321 respectively, which indicates that there is a moderate positive relationship between inflation and market turnover ratio. The negative relationship between inflation and the total value of shares, market capitalization, and all-shares index implies that as inflation decrease, these dependent variables increases. The result also indicates the highest positive relationship between exchange rate and market capitalization, which shows that, as the exchange rate increases, market capitalization decreases.

Table 2. Correlation Matrix.

\begin{tabular}{|c|c|c|c|c|c|c|c|}
\hline & NTVS & NMTOT & NMCA & NSAI & NINF & NEXCH & NINT \\
\hline NTVS & 1.737178 & -4.680262 & 6.417439 & 8.089632 & 3.925201 & -0.340263 & 3.128361 \\
\hline NNTOR & 2576422 & -4.730551 & 7.878682 & 8.286252 & 3.892840 & -0.099084 & 3.135494 \\
\hline NMCA & 6.130813 & -2.409566 & 9.730751 & 10.38559 & 5.348060 & 1.698443 & 3.806663 \\
\hline NASI & -6.151633 & -6.924473 & -0.460449 & 4.850936 & 3.167161 & -3.370668 & 2.564949 \\
\hline NINF & 2.885501 & 0.969509 & 3.071229 & 1.394657 & 0.509607 & 1.395214 & 0.380704 \\
\hline $\mathrm{NEXCH}$ & -1.110708 & 0.119739 & -0.642786 & -0.599826 & 0.743054 & -0.558599 & 0.300924 \\
\hline
\end{tabular}

\subsection{Stationarity Tests}

The stationarity or unit root test of the data used in this study was conducted using the Augmented Dickey-Fuller Test and the results are shown below. The study compared the test statistic value with that of test critical value at 5\% significance and considering $\mathrm{p}$-value and it has been indicated that three variables (MCA, ASI, EXCH, and INT) had unit-roots. This is because the absolute values of the ADF test statistic for each of these variables were less than the absolute variables of the test critical values at $5 \%$. In addition, the p-values corresponding to each of the ADF test statistics for these variables were greater than $5 \%$ $(0.400 ; 0.428 ; 0.193$ and 0.338$)$, respectively. In this case, the null hypothesis of no unit roots in the data series could not be rejected and therefore accepted. However, the variables with unit root have been transformed into the first difference to bring stationarity in these data, thereafter, the modified data were used in the regression model in the study.
Table 3. Result of Augmented Dickey-Fuller (ADF) Stationarity Test.

\begin{tabular}{llll}
\hline & ADF Test Statistics & Test Critical Value at 5\% & *P-Value \\
\hline NTVS & 3.952786 & 3.449020 & 0.013 \\
NNTOR & 7.066288 & 3.449020 & 0.000 \\
NMCA & 2.355441 & 3.449020 & 0.400 \\
NASI & 2.302945 & 3.450436 & 0.428 \\
NINF & 4.246044 & 3.449365 & 0.005 \\
NEXCH & 2.820507 & 3.450436 & 0.193 \\
NINT & 2.479754 & 3.449365 & 0.338 \\
\hline
\end{tabular}

*MacKinnon (1996) one-sided p-value.

Table 4. Result of Augmented Dickey -Fuller (ADF) Stationarity Test $1^{\text {st }}$ Difference.

\begin{tabular}{lllc}
\hline & ADF Test Statistics & Test Critical Value at 5\% & *P -Value \\
\hline NMCA & 6.610267 & 3.450436 & 0.000 \\
NASI & 3.934319 & 3.450436 & 0.014 \\
NEXCH & 9.621885 & 3.450436 & 0.000 \\
NINT & 6.162574 & 3.449365 & 0.000 \\
\hline
\end{tabular}

*MacKinnon (1996) one-sided p-value. 


\subsection{Regression Analysis}

The study used a Threshold Autoregression model proposed by $[30,14]$ to estimate the threshold level of inflation at which inflation will be harmful to the capital market performance. To achieve this objective, we continue to test for the threshold effects using annual growth of inflation as the threshold variable. This implies that, testing the null hypothesis of the linear model against the alternative hypothesis of the two - regime model. Since the threshold parameter $y$ is being unidentified test (such as the t-test) have non - standard distribution. [14] proposed a bootstrap method to stimulate the asymptotic distribution of the likelihood ratio test of the null hypothesis. The result of the threshold test and asymptotic p - values obtained through 1,000 bootstrap replications are reported in tables $1,2,3$, and 4 respectively

\subsubsection{Test Result of Inflation Threshold Effect and Threshold for Total Value Traded}

First of all, the study looked at the threshold effect. The examination also utilized the $F$ - test to analyze the correspondence of coefficients in two regimes and the $L R$ test also was employed to examine the equality of potential threshold values. The tables above show the test outcome and the bootstrap $\mathrm{p}$ - values for dependent variables under investigation. The measurements of $F_{1}$ are 27.023, 15.359, $30.467,39.497$, and 16.955 respectively, for determination, as $F 1$ surpasses the critical value at the $5 \%$ significance level, proposing one threshold level in any event. the further went on to analyze the chance of the presence of more than one threshold, and the test outcomes reject the one threshold's null hypothesis. This infers one inflation threshold value exists for all the reliant factors, which are $10.59 \%, 10.65 \%, 10.66 \%$, $10.70 \%$, and $10.69 \%$ respectively. The data on the growth rate of inflation is divided into low and high inflation regime.

Table 5. Estimated Result of Threshold and Significant Effect.

\begin{tabular}{llll}
\hline Null Hypothesis & F-Test & $\begin{array}{l}\text { Bootstrap } \\
\text { P-Value }\end{array}$ & $\begin{array}{l}\text { Estimated } \\
\text { Threshold }\end{array}$ \\
\hline Null of no Threshold & 27.0333 & 0.000 & $3.77 \%$ \\
Null of one Threshold & 90.1647 & 0.000 & \\
\hline
\end{tabular}

Notes: Estimation period is $1990 \mathrm{Q} 4$ to $2019 \mathrm{Q} 4$. Threshold variable is denoted as NINF. The thresholds are obtained by the minimum sum of the squared residual. The $\mathrm{F}$ test is calculated based on (15). “***, **, *” are significant for $1 \%, 5 \%$, and $10 \%$.

\subsubsection{Test of Inflation Threshold Effect and Threshold for Market Turnover}

Table 6. Estimated Result of Threshold and Significant Effect

\begin{tabular}{llll}
\hline Null Hypothesis & F-Test & $\begin{array}{l}\text { Bootstrap } \\
\text { P-Value }\end{array}$ & $\begin{array}{l}\text { Estimated } \\
\text { Threshold }\end{array}$ \\
\hline Null of no Threshold & 17.5651 & 0.004 & $4.14 \%$ \\
Null of one Threshold & & 0.000 & \\
\hline
\end{tabular}

Notes: Estimation period is 1990Q4 to 2019Q4. Threshold variable is denoted as NINF. The thresholds are obtained by the minimum sum of the squared residual. The $\mathrm{F}$ test is calculated based on (15). “***, **, *”, are significant for $1 \%, 5 \%$, and $10 \%$.

\subsubsection{Test Result of Inflation Threshold Effect and Threshold for Market Capitalization}

Table 7. Estimated Result of Threshold and Significant Effect.

\begin{tabular}{llll}
\hline Null Hypothesis & F-Test & $\begin{array}{l}\text { Bootstrap } \\
\text { P-Value }\end{array}$ & $\begin{array}{l}\text { Estimated } \\
\text { Threshold }\end{array}$ \\
\hline Null of no Threshold & 27.7990 & 0.004 & $4.22 \%$ \\
Null of one Threshold & & 0.000 & \\
\hline
\end{tabular}

Notes: Estimation period is 1990Q4 to 2019Q4. Threshold variable is denoted as NINF. The thresholds are obtained by the minimum sum of the squared residual. The $\mathrm{F}$ test is calculated based on $(15)$. “***, **, *" are significant for $1 \%, 5 \%$, and $10 \%$.

\subsubsection{Test Result of Inflation Threshold Effect and Threshold for All-Share Index}

Table 8. Estimated Result of Threshold and Significant Effect.

\begin{tabular}{llll}
\hline Null Hypothesis & F-Test & $\begin{array}{l}\text { Bootstrap } \\
\text { P-Value }\end{array}$ & $\begin{array}{l}\text { Estimated } \\
\text { Threshold }\end{array}$ \\
\hline $\begin{array}{l}\text { Null of no Threshold } \\
\text { Null of one Threshold }\end{array}$ & 28.8508 & 0.004 & $4.15 \%$ \\
\hline
\end{tabular}

Notes: Estimation period is 1990Q4 to 2019Q4. Threshold variable is denoted as NINF. The thresholds are obtained by the minimum sum of the squared residual. The $\mathrm{F}$ test is calculated based on (15). “***,**, *” are significant for $1 \%, 5 \%$, and $10 \%$.

\subsubsection{The results of Inflation Effect on Capital Market Performance in Single Threshold Model}

Table 9 below shows the estimated result of an inflation effect on capital market performance and performance has been measured with four variables which are: the value of share traded; market turnover ratio; market capitalization and all-shares index. In table 9, the first column shows the result of the effect of inflation on the value of shares traded. The result is divided into two regimes denoted by $\beta_{1}{ }_{1}$ and $\beta_{2}{ }_{2}$. In regime, one where inflation $3.77 \%$ the coefficient value (2.047) which is less than the threshold value indicates a positive significant relationship between inflation and the value of shares traded that one percent increase in inflation would result in a reduction in the value of shares traded by 2.047 percent. In regime two of the first column, where inflation $3.77 \%$ the coefficient value $(-0.136)$ shows the negative relationship between inflation and the value of shares traded and that a percentage decrease in inflation would increase the value of shares traded. However, the effect of inflation on the value of shares traded is statistically significant at $(2.05 \%)$ only in the low inflation regime (if $\mathrm{q} \leq 3.77 \%$ ). This means that inflation is only detrimental to the value of shares traded when it rises above the estimated threshold level. The second column of Table 9 shows the result of the effect of inflation on the market turnover ratio. In the table, where inflation $4.12 \%$ the coefficient value $(-0.094)$ shows the negative relationship between inflation and market turnover ratio and that a percentage decrease would result in an increase in the market turnover ratio by 0.094 percent. The result in the regime two also indicates that, where inflation $4.12 \%$ the coefficient value $(-1.216)$ also indicates the negative 
relationship between inflation and market turnover ratio, this implies that a percentage decrease in inflation would lead to an increase in the market turnover ratio. The effect of inflation in both regimes is negative but statistically significant in regime two. The estimated result in the third column of Table 9 indicates that where inflation 4.15 the coefficient value (1.330) shows a strong positive relationship between inflation and market capitalization and that a one percent increase in inflation would result in a reduction in market capitalization by $1.33 \%$. Where inflation $4.15 \%$ the coefficient value (1.460) also shows the positive relationship between inflation and market capitalization and that a one percent increase in inflation would result in a reduction in market capitalization of $1.460 \%$. The result of the effect of inflation on market capitalization in both regimes, one and two is positive and statistically significant in both inflation regimes. Lastly, the fourth column of Table 9 shows that, in regime one, where inflation $4.22 \%$ the coefficient value $(2.795)$ indicates the positive relationship between inflation and all-shares index and that a percentage increase in inflation would result in a reduction in the all-shares index by 2.795 percent. It has also been revealed in the regime two that where inflation 4.22 the coefficient $(0.308)$ shows the positive relationship between inflation and all-shares index that one percent rises in inflation would result in a reduction in the all-shares index by 0.308 percent. However, the effect of the inflation on the all-shares index is statistically significant in the low inflation regime (if $\mathrm{q} \leq 4.22$ and if $\mathrm{q}>4.22$ ). this implies that inflation is harmful to all- shares index when it rises above the estimated threshold level.

Table 9. Effect of Inflation on Capital Market Performance.

\begin{tabular}{|c|c|c|c|c|}
\hline Effect of Inflation on Performance & MTVS & MTOR & MCA & ASI \\
\hline$\beta^{\prime}{ }_{1}$ & $\begin{array}{l}2.047 \\
(1.045) * *\end{array}$ & $\begin{array}{l}-0.094 \\
(0.406)\end{array}$ & $\begin{array}{l}1.330 \\
(0.412) * *\end{array}$ & $\begin{array}{l}2.795 \\
(0.412) * *\end{array}$ \\
\hline$\beta_{2}^{\prime}$ & $\begin{array}{l}-0.136 \\
(0.449)\end{array}$ & $\begin{array}{l}-1.216 \\
(0.439) * *\end{array}$ & $\begin{array}{l}1.460 \\
(0.489) * *\end{array}$ & $\begin{array}{l}0.308 \\
(0.371)\end{array}$ \\
\hline
\end{tabular}

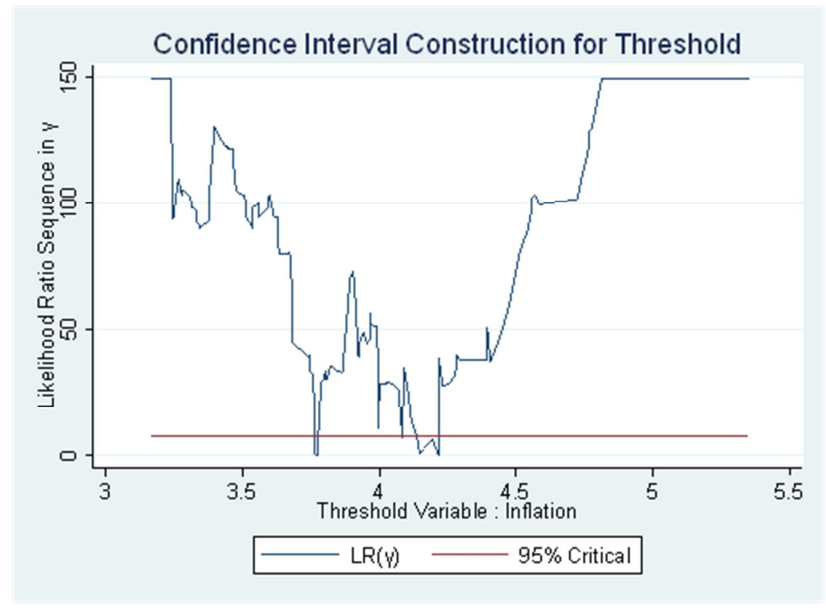

Figure 1. Confidence Interval for Market Value of Shares.

\subsubsection{The Result of Explanatory Variable and Capital Market Performance}

In table 10 below, the estimated result revealed a positive significant effect of exchange rate on the value of shares traded; market capitalization and all-shares index in the regime one of the models. The coefficient value $(1.941 ; 1.843$ and 0.418). In regime two, the result also indicates a statistically significant positive effect on all the dependent variables understudy with the coefficient value $(1.624 ; 0.711$; 1.569 and 1.000). The result shows a strong positive effect of exchange rate on capital market performance measures in both regimes suggesting that the exchange rate can equally harm the capital market performance.

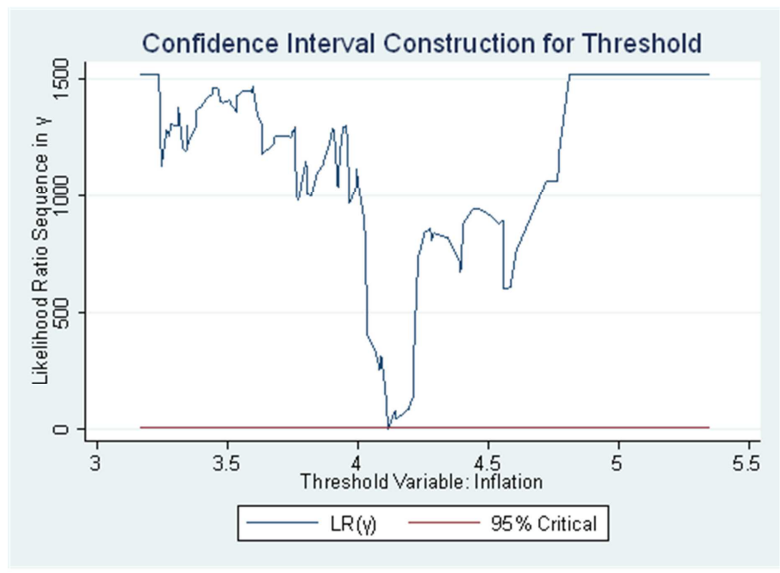

Figure 2. Confidence Interval for Market Turnover Ratio.

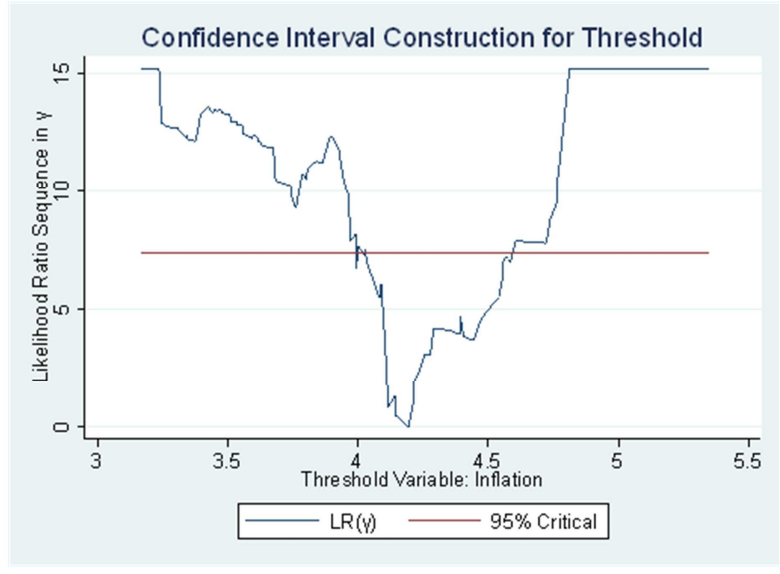

Figure 3. Confidence Interval for Market Capitalization. 
The result also shows that the interest rate has a negative effect on the value of shares traded; market capitalization and all-shares index and a positive effect turnover ratio in the regime, one with the coefficient value $(-3.535 ;-2.854 ;-2.940$ and 0.343$)$. In regime two, even though the result indicated the positive effect of interest rate on capital market performance, it has a statistically significant effect on the only turnover ratio and market capitalization with the coefficient value (1.597; 2.195) which is not all that strong as compared with the exchange rate.

Table 10. Effect of Explanatory Vasriable on Capital Market Performance.

\begin{tabular}{|c|c|c|c|c|}
\hline Effect of Inflation on Performance & MTVS & MTOR & MCA & Estimated Threshold \\
\hline \multirow[t]{4}{*}{ Constant } & 5.226 & -6.736 & 10.850 & 6.930 \\
\hline & $(3.249)$ & $(1.264)^{* *}$ & $(1.273) * *$ & $(0.998) * *$ \\
\hline & 2.309 & -3.554 & -8.456 & 5.341 \\
\hline & $(2.247)$ & $(2.839$ & $(3.283)^{* *}$ & $(2.453)$ \\
\hline \multirow[t]{4}{*}{$\mathrm{NEXCH}$} & 1.941 & -0.006 & 1.843 & 0.418 \\
\hline & $(0.128)^{* *}$ & $(0.078)$ & $(0.080)$ & $(0.063)^{* *}$ \\
\hline & 1.624 & 0.711 & 1.569 & 1.000 \\
\hline & $(0.157)^{* *}$ & $(0.409)^{* *}$ & $(0.203)^{* *}$ & $(0.152)^{* *}$ \\
\hline \multirow[t]{4}{*}{ NINT } & -3.535 & 0.343 & -2.854 & -2.940 \\
\hline & $(0.803)^{* *}$ & $(0.181)^{* *}$ & $(0.424)^{* *}$ & $(0.328)^{* *}$ \\
\hline & 0.173 & 1.597 & 2.195 & 0.491 \\
\hline & $(0.652)$ & $(0.789)^{* *}$ & $(0.887)^{* *}$ & $(0.328)$ \\
\hline R-Square & 0.843 & 0.327 & 0.926 & 0.784 \\
\hline Adjusted R- Square & 0.843 & 0.284 & 0.921 & 0.770 \\
\hline Number of Observation & 51 & 83 & 86 & 85 \\
\hline
\end{tabular}

Notes: Estimation period is 1990 Q4 to 2019 Q4. Threshold variable is INF\&. “**” and "“*” respectively represent $5 \%$ and $10 \%$ levels of significance. Values in parentheses are $t$ values.

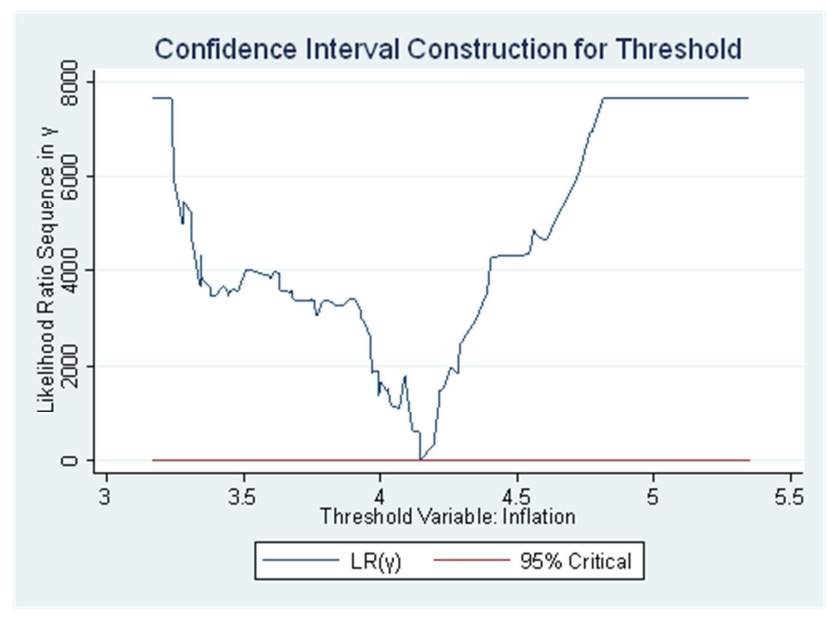

Figure 4. Confidence Interval for All-Shares Index.

\section{Conclusions, Discussion and Policy Implication}

In this empirical study, the study examined the effect of inflation on capital market performance by considering a threshold level of inflation. The study employed a threshold autoregression (TAR) model approach introduced by [30, 14] to establish the threshold effect of inflation on capital market performance. The study covered a period of thirty-years from 1990-2019. To estimate the threshold level, the paper used a $\log$ of inflation as a threshold variable in the model. The study estimates the threshold level of inflation from $3 \%$ to $4 \%$. The findings of this study show that there is one inflation threshold value and the result indicates that in the regime one, inflation is detrimental to the capital market performance. However, in regime two inflation is not harmful to capital market performance. The estimated result confirms the inflation situation in the Ghanaian economy. The empirical result further suggests that when the threshold level of inflation is above 3 to $4 \%$, inflation is detrimental to capital market performance. Besides, capital market performance is enhanced when inflation is below the threshold level estimated.

The result also suggests that the exchange rate can equally affect the performance of the capital market. In conclusion, the investment into the capital market would only be improved when the inflation rate is kept at a low or moderate rate. The empirical result in this study indicates that the inflationary threshold indeed exists in the relationship between inflation and capital market performance. However, the policy implication derived from this study is that governments and policy-makers to develop and implement microeconomic and macroeconomic policies that will enhance the performance of the capital market to stimulate economic growth in Ghana and developing countries. The findings of this investigation might be helpful to the government of Ghana and policymakers as they settle on an inflation target to adopt to avoid the detrimental effects of high inflation while reaping the growth benefits of low inflation.

\section{Acknowledgements}

I am most grateful to Almighty God for how He has brought me in this journey. I also thank Dr David Garr for his supervisory role played towards this work. Again, I thank Dora Agyekuma Ohenewaa for her support. 


\section{References}

[1] Ahortor, C. R. K., Adenekan, A., and Ohemeng, W. (2011), "An Estimate of Inflation Threshold in the WAMZ: The Case of Ghana and Nigeria", West African Journal of Monetary and Economic Integration, 11 (2), 158-201.

[2] Ayyoub, M. 2016. Inflation-Growth Nexus in Developing Economies: New Empirical Evidence from a Disaggregated, Working Paper Department of Economics Johannes Kepler University of Linz, No. 1602.

[3] Baglan, D., Yoldasz, E. 2014. Non-linearity in the Inflation-Growth Relationship in Developing Economies: Evidence from a Semiparametric Panel Model. Economics Letters, 125 (1): 93-96.

[4] Barro, R. J. 2013. Inflation and Economic Growth, Annals of Economics and Finance, 14-1: 85-109.

[5] Bose, B. (2002), "Inflation, the credit market, and economic growth," Oxford Economic Papers, 54, 412-34.

[6] Corrado, C. J. and Jordan, B. D. (2002). The Fundamentals of Investments Valuation and Management. 2nd ed USA, McGraw-Hill Companies Inc.

[7] Donwa, P., \& Odia, J. (2010). An Empirical Analysis of the Impact of the Nigerian Capital Market on Her Socio-economic.

[8] Emmanuel. E. \& Samuel sunday. (2012). The impact of inflation on stock market performance. American Journal of Social and Management Sciences, 20 (2151), 76-82.

[9] Espinoza, R. A., Prasad, A., Leon, M. H. 2010. Estimating the Inflation-Growth Nexus - A Smooth Transition Model, IMF Working Paper WP/10/76: 1-22.

[10] Jepkemei, B. (2017). The Impact of Inflation on Stock Market Liquidity: A Case of Nairobi Securities Exchange, Kenya. International Journal of Economics, Commerce and Management, 5 (1), 319-350.

[11] Fischer, S. (1993). The Role of Macroeconomic Factors in Growth. Journal of Monetary Economics, 32: 485-512.

[12] Frimpong, J. M. and Oteng-Abayie, E. F. (2010). When is Inflation Harmful? Estimating the Threshold Effect for Ghana. American Journal of Economics and Business Administration 2 (3): 232-239.

[13] Gylfason, T., \& Herbertsson, T. (2001). Does inflation matter for growth? Japan and the World Economy, 13 (4), 405-428. http://dx.doi.org/10.1016/S0922-1425(01)00073-1.

[14] Hansen, B. (1996), "Inference when a nuisance parameter is not identified under the null hypothesis," Econometrica, 64, 413-30.

[15] Hansen, B. E., 2000. Sample splitting and threshold estimation. Econometrica, 68: 575-603.

[16] Huybens, E. and D. S. Bruce, 1998. Financial market frictions, monetary policy and capital accumulation in a small open economy. J. Econ. Theory, 81: 353-400.

[17] Huybens, E., and B. Smith (1999), "Inflation, financial markets, and long-run real activity," Journal of Monetary Economics, 43, 283-315.

[18] Ibarra, R. and D. Trupkin (2016), "Reexamining the relationship between inflation and growth: Do institutions matter in developing countries?", Economic Modelling, 52, 332-351.

[19] Khan, M. S. and Senhadji, A. S. (2001). Threshold Effects in the Relationship between Inflation and Growth. IMF Staff Papers 48, 1-21.

[20] Kremer S., Bick A. and Nautz D. (2009). Inflation and Growth: New Evidence from a Dynamic Panel Threshold Analysis. SFB 649 Discussion Paper.

[21] Lee C., and S. Y Wong, (2005), "Inflationary threshold effects in the relationship between financial development and economic growth: evidence from Taiwan and Japan”, Journal of Economic Development, 30 (1), 49-68.

[22] Madurapperuma, M. W. 2016. Impact of inflation on economic growth in Sri Lanka, Journal of World Economic Research, 5 (1): 1-7. DOI: 10.11648/j.jwer.20160501.11.

[23] Ndoricimpa, Arcade. (2017), Threshold Effects of Inflation on Economic Growth in Africa: Evidence from a Dynamic Panel Threshold Regression Approach, Working Paper Series $N^{\circ} 249$, African Development Bank, Abidjan, Côte d'Ivoire.

[24] Nwankwo, G. O. (1991). Money and Capital Markets in Nigeria Today, University of Lagos Press Nigeria.

[25] Osaze B. E. (2009). Paradigm Shift Misplaced Concreteness and the Nigerian Financial System". Inaugural lecture series. 41. University of Benin. 40-41.

[26] Sarel, M. (1996), "Nonlinear effects of inflation on economic growth," IMF Staff Papers, 43, 199-215.

[27] Sepehri, A. and S. Moshiri. "Inflation-Growth Profiles Across Countries: Evidence from Developing and Developed Countries". International Review of Applied Economics 18, no. 2 (2004): 191-207.

[28] Snowdon (2005), Modern macroeconomics: Its Origin, Development and Current State. Edward Elgar Publishing Limited, United Kingdom.

[29] Thanh, S. D. 2015. Threshold effects of inflation on growth in the ASEAN-5 countries: A Panel Smooth Transition Regression approach, Journal of Economics, Finance and Administrative Science, 20 (38): 41-48.

[30] Tong, H. (1978), "On a threshold model: Pattern recognition and signal processing," Amsterdan: Sijthoff and Noordhoff, 101-41.

[31] Vinayagathasan, T. (2013). Inflation and economic growth: A dynamic panel threshold analysis for Asian economies. Journal of Asian Economics, 26, 31-41. 